\title{
ESKİ UYGUR BORÇ SÖZLEŞMELERİNE AİT SEKİZ FRAGMAN*
}

\section{EIGHT FRAGMENTS OF THE OLD UYGHUR LOAN CONTRACTS}

\section{Berker KESKINN** Öz}

Belirli şartlar altında daha sonra geri verilmek üzere alınan para ya da herhangi değerli bir şeyin karşıllğı olan borç, Eski Uygur toplumunda ihtiyaçların karşılanması için sıklıkla başvurulan alışveriş yöntemlerinden biridir. Mevcut sözleşmeler, Uygurların maddi ihtiyaç dışında arpa, buğday, pamuk gibi çeşitli tarımsal ürünler için de borçlandığını göstermektedir. Borcu alan ve borcu veren tarafların birlikte düzenlediği sözleşmeler geri ödeme şartları, kefalet ve tanıklık bilgisini içermektedir. Bu çalışma, BerlinBrandenburg Bilimler Akademisi, Turfan Koleksiyonu'nda muhafaza edilen

Anahtar Kelimeler Eski Uygur Türkçesi, hukuk belgeleri, ticaret, borç, faiz

Keywords

Old Uyghur Turkish, legal documents, commerce, loan, interest

** Arş. Gör. Dr., İstanbul Üniversitesi, Edebiyat Fakültesi Türk

Dili ve Edebiyatı Bölümü berker.keskin@istanbul.edu.tr ORCID: 0000-0001-8599-286X İstanbul / TÜRKIYE

Gönderim Tarihi: 06/10/2020 Kabul Tarihi: $\quad$ 22/03/2021 sekiz farklı borç sözleşmesine ait fragmanların yayınını konu edinmektedir. Öncelikle borç sözleşmelerinin genel özellikleri ortaya konmuştur. Fragmanların yazı ve harf çeorimi yapılmış, ardından Türkiye Türkçesine aktarılmıştır. Gerekli görülen yerlere notlar eklenen çalışmanın sonunda metinlere ait bir dizin ile tipkıbasımlar yer almaktadır.

\section{Abstract}

A Loan, which is the money or something valuable received to be given back under certain conditions, was one of the most frequently used trade ways to provide needs in the Old Uyghur society. Present contracts show that Uyghurs also borrowed for various agricultural products such as barley, wheat, and cotton in addition to the financial requirements. The loan contracts were issued by the debtor and the lenders together. They comprised the repayment conditions, surety and testimony information. This study is about the publication of the fragments of eight different loan contracts preserved in the Turfan Collection in the Berlin-Brandenburg Academy of Sciences and Humanities. In the first instance, the main specialties of the loan contracts have been determined. The fragments have been transcribed, transliterated and then they have been translated into Turkey Turkish. Descriptor notes have been added where necessary. At the end of the study, there is an index of the texts and facsimiles.

* Bu makale, Eski Uygur Türkçesi Hukuk Belgeleri ve Söz Varlığı adlı Doktora tezine dayanarak hazırlanmıştır. İlgili tez çalışması, İstanbul Üniversitesi Bilimsel Araştırma Projeleri Birimi (Proje No: SDK-2017-25682) ve TÜBİTAK tarafından da desteklenmiştir. 


\section{GİRIş}

Eski Uygur Türkçesi hukuk belgeleri, Uygurların çeşitli ticari faaliyetleri (satış, takas, kira, borçlanma vb.) hakkında düzenlenmiştir. Bununla birlikte vasiyetnameler, dilekçeler, raporlar, makbuzlar ve buyruklar gibi farklı yapı ve içeriklere sahip belgeler de yine resmi bir karakter taşıdığından hukuk belgeleri arasına dâhil edilmektedir. Uygurlardan günümüze ulaşan edebi külliyatın yanı sıra bu belgeler de devrin dilinin anlaşılması ile ticari ve ekonomik yaşamın varlığı hakkında çeşitli bilgiler sunmaktadir.

Hukuk belgeleri üzerine XIX. yüzyılın sonlarından itibaren çalışmalar gerçekleştirilmeye başlanmıştır. Ancak bunların tamamının burada değerlendirilmesi mümkün olmadığından yalnızca öncü çalışmalar ile kapsamlı metin neşrini içeren kitap yayınları hakkında bilgi verilecektir. İlk olarak Wilhelm Radloff, "Altuigurische Sprachproben aus Turfan" adlı makalesinde iki hukuk belgesinin yayınını gerçekleştirir (Radloff, 1899). Bunu, 1906 yılında yirmi üç belgenin transkripsiyon ve Almanca tercümesini içeren "Uigurische Schriftstücke, in Text und Übersetzung" adlı makalesi takip eder (Radloff, 1906). Ancak Radloff'un konu hakkında en kapsamlı çalışması, bugün dahi bir başvuru kaynağı olarak kullanılan Uigurische Sprachdenkmäler adlı eseridir (Radloff, 1928). Ölümünden sonra öğrencisi Sergey Malov tarafından düzenlenen eserde 128 belge yer almaktadır ve bunlardan 101'i din dışı içeriğe sahiptir.

Malov'un Eski Uygur hukuk belgeleri araştırmalarına katkısı USp'yi yayına hazırlamakla sınırlı değildir. Turfan'da bulunduğu sırada satın aldığı borç ve köle satışı hakkında düzenlenmiş iki belgeyi 1927 yılında "Dva Uygurskih Dokumenta" adıyla yayınlamıştır (Malov, 1927). Ayrıca 1932'de yayınlanan bir başka makalesinde Oldenburg koleksiyonuna ait beş belgenin dökme harflerle transliterasyonunu, Latin harfli transkripsiyonunu ve Rusça tercümesini yapmıştır (Malov, 1932). Ayrıca Pamyatniki dreonetyurkskoy pis'mennosti adlı eserinde daha önce USp' de yayınlanan dört belgeyi tekrar gözden geçirmiş ve iki yeni belge daha yayınlamıştır (Malov, 1951).

Gustav John Ramstedt'in Finlandiya' da muhafaza edilen dört Eski Uygurca belgeyi transkripsiyon, İngilizce tercüme ve tıpkıbasım olarak yayınladığı "Four Uigurian Documents" adlı makalesi, içeriğindeki üç hukuk belgesinin ilk kez bilim dünyasına tanıtılması bakımından önem taşır (Ramstedt, 1940).

Reşit Rahmeti Arat, 1964 yılında yayınladığı “Eski Türk Hukuk Vesikaları" adlı çalışmasında belgelerin formülleri, sınıflandırılması, niteliği gibi konular hakkında bilgi vererek sekiz hukuk belgesinin transkripsiyonunu ve Türkiye Türkçesine aktarımını gerçekleştirir (Arat, 1964).

Larry V. Clark 1975'de hazırladığ1 ve Introduction to the Uyghur Civil Documents of East Turkestan ( $\left(3^{\text {th }}-14^{\text {th }} \mathrm{Cc}\right.$.) başlığını taşıyan Doktora tezinde 141 belgeyi incelemiş, daha önce yapılan çalışmalar, formüller ve belgelerin ses bilgisi ile gramer özellikleri gibi konular hakkında bilgi vermiştir (Clark, 1975).

Peter Zieme, yazdığı makaleler ile hukuk belgeleri araştırmalarına büyük katkılar sunmuştur. Bunlar arasında Eski Uygurlarda kira, vergi muafiyeti gibi konular hakkında düzenlenenler olduğu gibi metin neşrine dayanan makaleler de vardır. Bu 
bakımdan pek çok hukuki içerikli belgenin Türkoloji sahasına ilk kez bu çalışmalarla tanıtıldığını belirtmek gerekir.

Japon Türkolog Nobuo Yamada'nın Sammlung uigurischer Kontrakte adlı üç ciltlik çalışması ise bu alandaki en kapsamlı çalışmalar arasında yer alır. İlk ciltte Yamada'nın konu hakkında daha önce yayınlanmış makaleleri yer alırken ikinci cilt, 121 hukuk belgesinin transkripsiyonunu, Japonca ve Almanca tercümelerini, ayrıca bir dizini ihtiva eder. Üçüncü cilt ise belgelerin tıpkıbasımına ayrılmıştır (Yamada, 1993).

Dai Matsui, Mongoru jidai Uigurisutan no monjo gyōsei to zeisei, ekidensei. Uigurubun kyōshutsu meirei monjo wo chūshin to shite [=Moğol Yönetimi Altında Uyguristan'da Yönetim] (Matsui, 1996) ve Mongoru jidai Uigurisutan no zeieki seido to monjo gyōsei [=Moğol Yönetimi Altında Uyguristan'da Vergilendirme ve Yönetim Sistemleri (13-14. Yy.)] (Matsui, 1999) adlı Yüksek Lisans ve Doktora tezlerinde sirasiyla 47 ve 54 belgenin transkripsiyon ve Japonca tercümelerini yapmıştır.

Simone-Christiane Raschmann'ın 1995 yılında yayınlanan Baumwolle im türkischen Zentralasien, Philologische und wirtschaftshistorische Untersuchungen anhand der vorislamischen uigurischen Texte adlı çalışması, Orta Asya'da İslamiyet öncesi dönemde Türkler arasında pamukçuluk, pamuğun özelliği, işlenmesi ve kullanım şekilleri gibi konular hakkında hazırlanmıştır. Çalışmanın sonunda 113 din dışı Eski Uygurca belgenin künyesi verilerek böz "pamuklu kumaş" ile ilgili kısımlarının transkripsiyonu ve Almanca tercümesi gerçekleştirilmiştir (Raschmann, 1995). Ayrıca Raschmann'ın Almanya'da muhafaza edilen din dışı içerikli Uygur belgeleri hakkında hazırladığ Alttürkische Handschriften Teil 13, Dokumente Teil 1 ve Alttürkische Handschriften Teil 14, Dokumente Teil 2 adlı kataloglar, belgelerin kayıt numaraları, içeriği ve daha önce yapılan çalışmalar hakkında bilgiler içermesi bakımından kaynak eser olma özelliği gösterir (Raschmann, 2007 ve Raschmann, 2009).

Liliya Yusufcanovna Tuguşeva tarafından 2013 yılında yayınlanan Uygurskie delovye dokumenty X-XIV. iz Vostoçnogo Turkestana adlı eserde 97 belgenin transkripsiyonu, Rusça tercümesi, çeşitli açıklamalar, dizin ve tıpkıbasım içermektedir (Tuguşeva, 2013).

Márton Vér tarafindan hazırlanan ve The Postal System of the Mongol Empire in Northeastern Turkestan başlı̆̆ını taşıyan Doktora tezi, 63 Eski Uygur buyruğunun değerlendirmesini içermesi bakımından önemlidir (Vér, 2016).

Son olarak, İstanbul Üniversitesi Sosyal Bilimler Enstitüsü'nde tarafımızdan hazırlanan ve Eski Uygur Türkçesi Hukuk Belgeleri ve Söz Varlığı adını taşıyan Doktora tezinin esasını 500'den fazla metnin transkripsiyonu, Türkiye Türkçesine aktarımı, söz varlığ1 ve dizini oluşturur. Bütün bunlara ek olarak değerlendirilen belgelerden hareketle Eski Uygur hukuk sistemi üzerine bir bölüm oluşturulmuş ve hukuk belgeleri hakkında yapılan çalışmaların tarihi incelenmiştir (Keskin, 2020). Burada değinilemeyen diğer çalışmalar hakkında tezin ilgili bölümüne müracaat edilebilir.

Bu makale, yukarıda adı bulunan Doktora tezinden faydalanılarak hazırlanmıştır. Tezin Borç Belgeleri bölümünde değerlendirilen ve kataloglar haricinde herhangi bütünlüklü bir bilimsel çalışmanın bulunmadığı sekiz fragmanın yazı ve harf çevrimi, Türkiye Türkçesine aktarımı gerçekleştirilmiş, bunlar vasıtasıyla Eski Uygur borç 
sözleşmelerinde yer alan ortak hukuki terimler açıklanmıştır. Ayrıca gerekli görülen yerlere notlar eklenerek çalışmanın sonunda fragmanlara ait tıpkıbasımlara yer verilmiştir.

\section{ESKİ UYGUR BORÇ SÖZLEŞMELERİNIN TEMEL ÖZELLIKKLERİ}

Eski Uygur hukuk belgelerinin önemli bir bölümünü oluşturan borç sözleşmeleri, Uygur toplumunun hangi şartlar altında ve ne şekilde borç alıp verdiğinin anlaşılması konusunda yeterli niteliğe sahiptir. Alım-satım ve takas gibi diğer ticari içeriklere sahip sözleşmelerle mukayese edildiğinde daha dar bir hacme sahip olan borç sözleşmelerini farklı kılan en önemli hususiyetler, kefalet ve faiz kavramı hakkında bilgi vermesidir. Öyle ki ticari amaçla düzenlenmiş diğer hiçbir belge çeşidinde kefillere dair herhangi bir kayıt bulunmamaktadır. Aynı şekilde faiz için kullanılan karşılıklar ve faiz yapıları da ancak borç sözleşmelerinden hareketle anlaşılabilmektedir.

Eski Uygurlarda borçlanmanın genellikle iki farklı yöntem ile gerçekleştirildiği tespit edilmiştir. Buna göre parasal borç durumunda geri ödemenin yapılacağ1 tarih çoğunlukla belirtilmemiş, ancak ödemenin olmadığı her ay için faiz ekleneceği yazılmıştır. Sadece iki sözleşmede borcun geri ödeme tarihinin belirtildiği ve faiz için başınta ur- deyiminin kullanıldığı görülmüştür. İkinci olarak ise buğday, pamuk gibi ayni borçlanmalarda bu kez geri ödemenin yapılacağı dönem belirtilmiş ve bu olmazsa

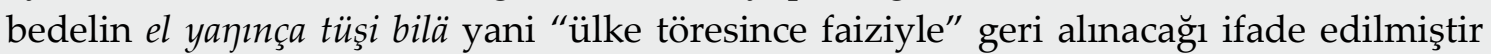
(Keskin, 2020, s. 29).

Sözleşmelerin genel düzenlenişine uygun bir biçimde borcun geri ödenmemesi durumunda ya zımnî olarak hane halkı işaret edilmiş ya da hane halkından birinin adı borçluya olan akrabalığı da açıklanarak belirtilmiştir. Bu sayede kefil ya da kefiller ortaya konmuş, alacaklıya karşı bir teminat oluşturularak borçlunun geri ödeme yapmaması durumunda sorumluluk adı geçen üçüncü şahıslara yüklenmiştir:

berginçä yok [ba]r bolsar-m(ä)n kişim tüzük köni berz-ün (U 5230 6-8)

"Verinceye kadar ölürsem eşim Tüzük, doğru bir şekilde versin."

böz berginçä yok bar bolsar ävt(ä)ki-lär köni berz-ün (U 5231 8-9)

"Bözü verinceye kadar ölürsem evdekiler doğru bir şekilde versin." be<r>ginçä bar yok bolș-a m(ä)n inim ıdaba äv-täki-lär bilä köni berẓün-lär (U52526-8)

"Verinceye kadar ölürsem küçük erkek kardeşim Idaba, evdekilerle beraber doğru bir şekilde versin."

berginç-ä bar yok bolsar-m(ä)n oglum tämür buk-a äv-täki-lär bilä köni berẓün-l(ä)r (U 52629-11) "Verinceye kadar ölürsem oğlum Tämür Buka, evdekilerle beraber doğru bir şekilde versin."

bu tarıg berginçä örü kudı bolsar-m(ä)n [... (Ch/U 6992v4)

"Bu tahılı verinceye kadar ortadan kaybolursam..."

berginçä örü kuḍ bolsarm(ä)n inim biläy köni berẓün (SI Kr. IV/3295-6)

"Verinceye kadar ortadan kaybolursam küçük erkek kardeşim Biläy doğru bir şekilde versin."

berginçä yok bar bol- / örü kudı bol- $+\underline{\text { kefil adı }}+$ köni ber- kalıp ifadesine ek olarak bazı sözleşmelerin “kefil” karşılığı taypaoşın (<Çin. 代保人 dài băo rén) ve paoşın (< Çin. 
保人 băo rén) terimlerini içerdiği görülmektedir. ${ }^{1}$ Borcun ödenmesi hakkındaki sorumluluğu üstlenerek birinci ağızdan bunu belirten kişiler özellikle taypaoşın olarak nitelendirildiği için bunu "müteselsil kefil" şeklinde anlamlandırmak mümkündür:

bu bitig-däki çao-nı berginçä biz enç buk-a arug iştin taştın bar yok bolsar-biz birlä alguçı

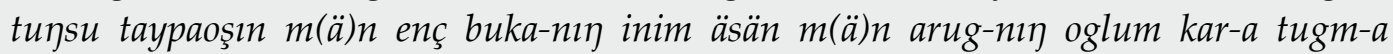
ikägü bu bitig-täki çao-nı bitig yosunça nägü-kä-m-ä tıldamayın çam-sız köni berür-biz (*U 918110-16)

“Bu sözleşmedeki çaoyu verene kadar Enç Buka ve Arug ortadan kaybolursa müşterek borçlu, müteselsil kefil (olarak) ben Enç Buka'nın küçük erkek kardeşi Äsän ve ben Arug'un oğlu Kara Tugma, ikimiz bu sözleşmedeki çaoyu senet kanununca hiçbir bahane aramadan itirazsız doğru bir şekilde veririz."

berginçä $m(\ddot{)}) n$ ırsul yok bar bols(a)r-m(ä)n bu bugday-nı birlä alguçı tuך-su tay-paoşın $m(\ddot{a}) n$ sul(a)ym(a)n öz bodum-tın köni berür-m(ä)n (SI Kr. I/1478-12)

“Verinceye kadar ben Irsul, ölürsem bu buğdayı müşterek borçlu, müteselsil kefil Sulayman kendisinden doğru bir şekilde verecektir."

Yukarıda iki farklı sözleşmeden sunulan örneklere dikkat edilirse şahıs adlarını niteleyen taypaoşın'dan önce birlä alguçı ve tuๆsu (< Çin. 同取 tóng qǔ) sözcüklerinin sıralandığı görülür. Tuๆsu "müşterek borçlu" olarak anlamlandırılırken (Yamada, 1993, s. 294; Matsui, 2004, s. 199) birlä alguçı, bu sözcügün Eski Uygur Türkçesine tercümesinden başka bir şey değildir. Zira tuๆsu, tóng 同 30:3 “benzer, birlikte" (Pulleyblank, 1991, s. 310) adı ve qǔ 取 29:6 “almak" (Pulleyblank, 1991, s. 261) eyleminden oluşmuş hukuki bir terimdir.

Faiz kavramı ise borç sözleşmelerinde asıg ve tüş sözcükleriyle karşılanmıştır. Aşağıda incelenecek olan metin parçalarında bunların her ikisi de yer aldığından ilgili açıklamalar notlar kısmında bulunmaktadır (bk. B4 ve F2).

Ayrıca sözleşmelerin çok az sayıdaki örneğinde "borç" anlamında ötünü sözcüğünün bulunduğu tespit edilmiştir:

yılan yıl ikinți ay on iki-kä mạa ırsul-ka ötünü bugday k(ä)rgäk bolup yabagu-tın öẓinị şıgı birlä (SI Kr. I/1471-4)

"Yılan yılı ikinci ayın on ikisinde bana, Irsul'a borç (olarak) buğday gerekli olup Yabagu'dan kendisinin ölçüsüyle..."

Sözleşmelerde ticari bir terim olarak kullanılan sözcüğün DLT'de ötnü “ödünç, borç" olarak tanıklandığı, bunun yanı sıra aynı kökten türetilen ötünç "borç" ile ötnü ber- "borç vermek" ifadesinin de yine DLT'de yer aldığı görülmektedir (ErcilasunAkkoyunlu, 2014, s. 66).

\section{METIN, TERCÜME VE NOTLAR}

\subsection{Metin A: Ch/U 6527 v (T I D 51)}

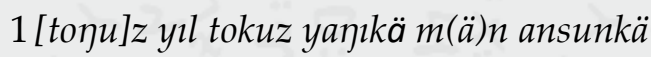

[ ]z yyl twqwz y'nky k' mn "nswn k'

2[ kärgäk] bolup on alțun aldım $m(\ddot{a}) n$ ansun

Terimleri meydana getiren sözcüklerin Pulleyblank'taki görünümü için bk. dài 代 9:3 (1991, s. 69), băo 保 9:7 (1991, s. 30), rén 人 9:0 (1991, s. 265). 


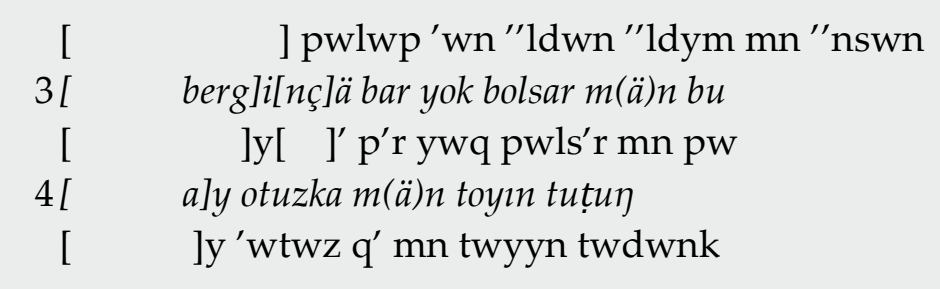

1-2Domuz yılı dokuzuncu günde ben Ansun'a [...] gerekli olup on altın aldım. ${ }^{3-4} \mathrm{Ben}$ Ansun $[\ldots]$ verinceye kadar ölürsem bu [...] ayın dokuzuncu gününde ben Toyın Tuțun $[\ldots]$

\section{Notlar:}

A1, ansun: Transliterasyonu "nswn şeklinde kalın sıralı olan şahıs adına gelen yönelme hali ekinin $\left\{-\mathrm{Q}^{\prime}\right\}$ olması beklenirken ince sıralı biçimde $\left\{-\mathrm{K}^{\prime}\right\}$ eklenmiştir. Aynı şekilde belgede yer alan yaクı sözcüğ̈̈ne gelen ek de ince sıralıdır. Bu gibi kök ve ek uyumsuzlukları hukuk belgelerinde rastlanılabilir bir durumdur. ${ }^{2}$

A3, bar yok bol-: Eski Uygur borç sözleşmelerinde yer alan standart deyimlerden biri olan bu ifade biçimi, alacaklının haklarını korumak için sözleşmelere eklenmiştir. "Var-yok olmak" ile borçlunun hayatını kaybetme ihtimali kastedilmiş ve böyle bir durum gerçekleşirse borcun kim tarafından üstlenileceği hakkında bilgi verilmiştir. Bar yok bol- dışında yok bar bol- şeklinde de sözleşmelerde tespit edilen bu deyimin ardından kefalet bilgisi gelmektedir.

A4: Belgede yer alan dördüncü satır, ilk üç satırın devamını oluşturmamaktadır. Diğerlerinden ayrı, daha aşağıda yazıldığı gibi imla da farklıdır ve tarih ile şahıs adı bilgisi içermesinden dolayı ayrı bir sözleşmenin başlangıç formülü olduğu anlaşılmaktadır.

\subsection{Metin B: Ch/U 7358 v (Glas: T II T 1972)}

$1 \ldots] M /[\ldots$

$\ldots] \mathrm{m} /[\ldots$

$2 \ldots \ddot{u}]$ çünç ay $/[\ldots$

...] $c_{\text {'̧ }}$ wynç $" \mathrm{y} /[\ldots$

$3 . ..] K^{\prime}$ äsän $[\ldots$

$\ldots] \mathrm{k}$ ' 's'n $[\ldots$

$4 \ldots]$ tüşkä $[\ldots$

.... t'wyş k' $[\ldots$

5 .... bolup ok [...

...] pwlwp'wq [...

$6 \ldots]$ şıg tarı $[\ldots$

...]s şyq t'ryq $[\ldots$

${ }^{1-6}[\ldots]$ üçüncü ayın $[\ldots]^{\prime}$ a Äsän $[\ldots]$ faiz (karşlığında) [...] olup bizzat $[\ldots]$ şıg tahil $[\ldots]$

2 Örnek olarak bk. takıgu yıl onunç ay bir otuz-ka maja mısır-kä (U 32803). bu t(a)vgaç küin-ta (*U 9003 ri) 


\section{Notlar:}

B4, tüşkä: Sözleşmelerde tarih bilgisinden sonra borçlunun adıyla birlikte neye gereksinim duyduğu ve bunun ancak "faiz" karşıllğı alınacağ tüş+kä / asıg+ka + ürün

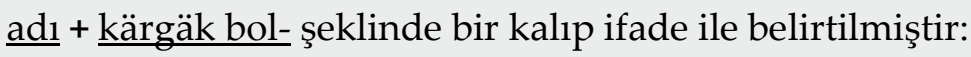

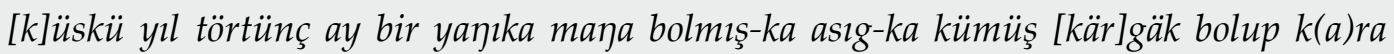
ogul-ta altı s( $($ )tır [k] ̈̈̈müş altım (U 52301-4)

"Sıçan yılı dördüncü ayın birinci gününde bana, Bolmış'a faiz karşılığında gümüş gerekli olup Kara Ogul'dan altı sıtır gümüş aldım."

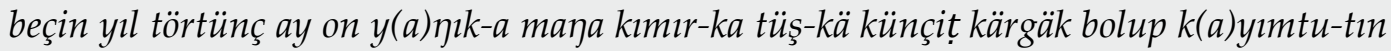
tört şiๆ künçiț aldım (U 52521-4)

"Maymun yılı dördüncü ayın onuncu gününde bana, Kımır’a faiz karşılığında susam gerekli olup Kayımtu'dan dört şin susam aldım."

Temel anlamı "meyve, yemiş" olan tüş, borç sözleşmelerinin genelinde "faiz, getiri" anlamına gelecek şekilde kullanılmıştır. ED'de sözcüğün temel anlamının "meyve" olmasına rağmen metaforik olarak "yapılan işin sonucu" veya "iyi bir davranış karşılığında alınan ödül” anlamında kullanıldığı açıklanmaktadır (1972, s. 558b). Bununla birlikte DTS'de de sözcügün "meyve, yemiş" anlamı dışında "ücret, gelir, faiz" anlamlarına geldiği ifade edilmektedir (1969, s. 600a). Gerek tüş gerekse asıg, sözleşmelerde genellikle müstakil bir kullanıma sahip olmasına rağmen $\mathrm{Ch} / \mathrm{U}$ 6992'de her iki sözcüğün birlikte ikileme olarak yer aldığı görülmektedir: yałı-ta asıgı tüşi b[i]l[ä köni] berürm(̈̈)n (Ch/U 6992 v3-4) "Zamanında faiziyle doğru bir şekilde veririm."

B6, şıg: Pek çok Eski Uygur belgesinde görüldüğü üzere şıg arpa, buğday ve darı gibi hububatlar için kullanılmış bir çeşit hacim ölçüsüdür (ED, 1972, s. 867b). Borç sözleşmeleri dışında satış, kiralama, vasiyetname ve buyruklar gibi farklı içerikteki belgelerde rastlanabilen sözcük, bazı durumlarda sözleşmeye konu olan arazide yetiştirilebilecek tarımsal ürün miktarı bakımından arazi niteliğini belirlemek için de kullanılmıştır: eçim kançuk bilä tüz ülüşlüg iç [=

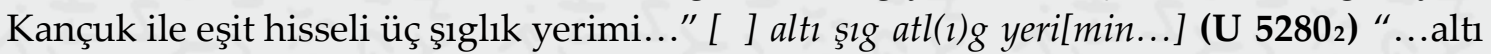
şıglık yerim ile..." Eski Uygur Türkçesine Çinceden geçen şıg (< 石 shí, GOÇ. shiajk) kaynak dilde "taş, kaya" anlamına sahiptir (Pulleyblank, 1991, s. 283) ve yaklaşık 84 litreye denk gelmektedir (Matsui, 2004, s. 200).

\subsection{Metin C: So 10239 (4) v (T I a)}

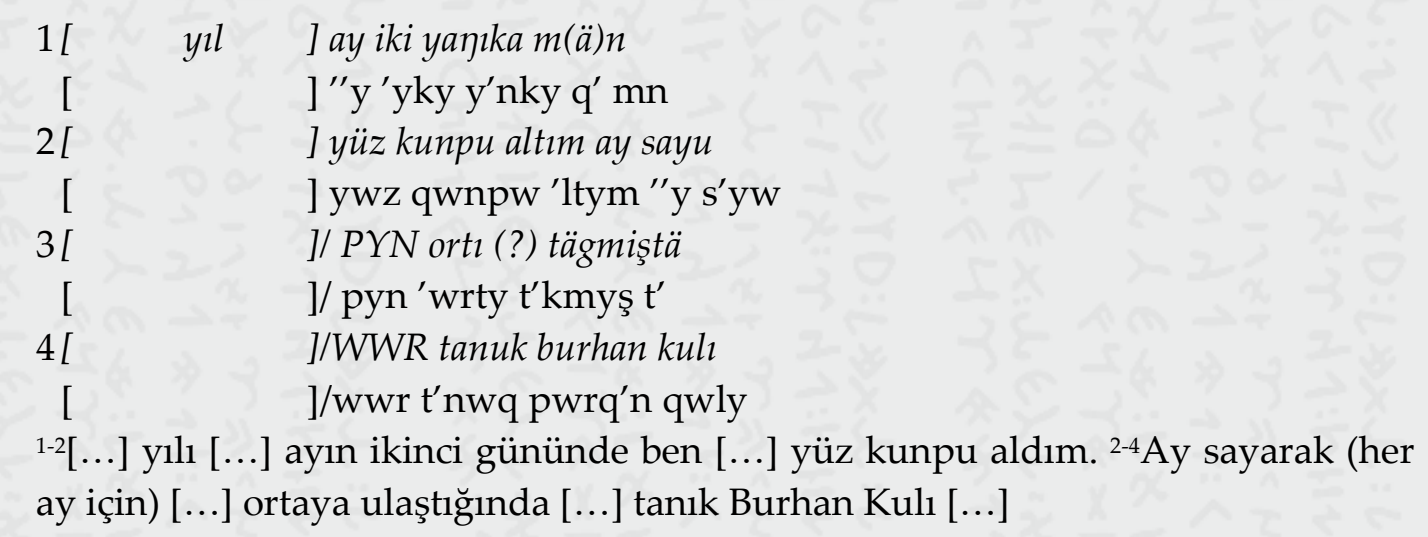




\section{Notlar:}

C2, kunpu: Para yerine kullanılan kuanpu, böz ile birlikte Eski Uygur sözleşmelerinde en sık karşılaşılan ödeme araçlarının başında gelmektedir. Özellikle satış sözleşmelerinde tarla, bağ ya da bahçelerin pek çoğunun kuanpu ihtiyacı doğrultusunda elden çıkarıldığı beyan edilmiştir. Sözcügün hukuk belgelerinde standart bir imlası bulunmamakta, kuanpu olması beklenirken kanpu ya da bu metinde olduğu gibi kunpu şeklinde bir imlaya rastlanabilmektedir. ${ }^{3}$ Temel olarak "resmi kumaş" anlamına gelen sözcük, Eski Uygur Türkçesindeki bir diğer Çince alıntıdır (< guān bù, GOÇ. kuan puă). Birleşik yapıdaki bu sözcük ile ilgili olarak bk. guān 官 40:5 (Pulleyblank, 1991, s. 113) ve bù 布 50:2 (Pulleyblank, 1991, s. 42).

\subsection{Metin D: U 5552 (T II D 56)}

1 [ar]pa al[dim...

[ ] $p^{\prime \prime \prime} 1[\ldots$

2 şı $\operatorname{arpa}[$ [köni berür män...

şyq "rp' [...

3 bermädin käçür[sär män...

pyrm'dyn k'çwr[...

4 sulțan 'ävt(ä)ki[lär birlä köni berzün...

swld'n "v tky[...

${ }^{1}$ arpa aldım [... $]^{2-3}$ şıg arpayı doğru bir şekilde veririm [...] vermeden (zaman) geçirirsem [...] ${ }^{4}$ Sulțan, evdekilerle birlikte doğru bir şekilde versin [...]

\section{Notlar:}

D4, sulțan: Eski Uygur hukuk belgeleri, içeriğinde yer alan şahıs adlarıyla Türk onomastiği için eşsiz bir kaynaktır. Bu adlar incelendiğinde Türkçe olanlar dışında Sanskrit veya Çin kökenli adların da yoğunluk taşıdığı görülür. Daha geç dönemde hazırlanan sözleşmelerde ise İslamiyet'in etkisiyle Arapça ve Farsça kökenli sözcüklerin kullanım sıklığı artmıştır. Burada da sultan sözcüğünün Eski Uygurlar döneminden itibaren Türk milleti tarafından bir şahıs adı olarak kullanılmaya başlandığını görmek mümkündür (< Ar. sulțān "hükümdar, padişah).

D4, ävtäkilär: Borç sözleşmelerinde yer alan kefalet bilgisi bölümünde borçlu, yukarıda daha önce değinildiği gibi alacaklıya karşı bir teminat oluşturmaktadır. İşte burada, borçlunun ailesinin tamamı zımnen ävtäkilär "evdekiler, evde bulunanlar" ibaresiyle yapilan işten, geri ödemeden sorumlu tutulmuştur. Radloff'tan başlamak üzere birçok araştırmacı uzun süre bu sözcügün yazı çevrimini ve tercümesini farklı bir şekilde yapmıştır. Buna göre genellikle ävtäkilär sözcügünün kökü tamlayan eki olarak düşünülmüş ve önce gelen şahıs adına eklenmiş; geri kalan eklerin $\{+\mathrm{DA}+\mathrm{ki}+\mathrm{lAr}\}$ yazı çevrimi ise tägi-lär şeklinde yapılarak buna "akrabalar; soyundan gelenler, varisler" gibi anlamlar verilmiştir. Dolayısıyla ilgili sözcügün yer aldığı ibare “(şahıs adı)'nın akrabaları; soyundan gelenler" olarak tercüme edilmiştir (Radloff,

Sözcüğün sahip olduğu imla farklılıkları ile ilgili olarak örn.

kuanpu $\rightarrow$ yu l(a)k-lık kuanpu k(ä)rgäk bolup (U 52412)

kanpu $\rightarrow$ yüz älig kanpu berür-män (U 52334)

kunpu $\rightarrow$ yuๆlak-lık kunpu kärgäk bolup (U 39082) 
1906, s. 184; Le Coq, 1918, s. 455; Malov, 1927, s. 390; USp, 1928, s. 7). Hatta Ahmet Caferoğlu'nun Uygur Sözlüğü'nde tägi madde başında yer alan ilk açıklama, USp'den ve Malov'un "Dva Uygurskih Dokumenta" adlı makalesinden hareketle "akraba, hısım" şeklindedir (Caferoğlu, 1938, s. 177). Ancak daha sonra bu transkripsiyon ve anlamlandırma, Yamada tarafından düzeltilerek açıklanan halini almıştır (Yamada, 1965, s. 175-178).

\subsection{Metin E: U 5825 (Glas: T III 517)}

$1 \ldots] / /[\ldots$

$\ldots] / /[\ldots$

$2 \ldots] /$ berginçä biz ikigü örü kudı bols(a)r biz.

...]/ pyrkynç' pyz 'ykykw 'wyrw qwdy pwlsr pyz.

3...]P'K taş. inim kurumış bilä köni berzün

...]p'k t'ş. 'ynym qwrwmyş pyl' kwyny pyrz wn

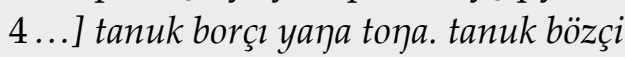

5...] kulı bu t(a)mga biz törtägünü ol

...] t'nwq pwrçy y'nk' twnk'. t'nwq pwyzçy

...] qwly pw tmq' pyz twyrt'kw nwnk 'wl

1-3[...] verinceye kadar biz ortadan kaybolursak [...] Taş, küçük erkek kardeşim Kurumış ile doğru bir şekilde versin. ${ }^{4-5}$ Tanık şarap tüccarı Yana Tona. Tanık dokumacı [...] Kulı. Bu damga, biz dördümüzündür.

\section{Notlar:}

E2, örü kudı bol-: Sözleşmelerde bar yok bol- deyiminin yerine kullanılabilen örü kudı bol- "ortadan kaybolmak, kaçıp gitmek" anlamına sahiptir. Bu bakımdan ilgili deyimin borcunu ödeme konusunda kendisine çok da fazla güvenilmeyen kişiler için kullanıldığını düşünmek mümkündür. Zira deyimin ardında ödeme yükümlülüğü yine üçüncü şahıslara aktarılmıştır.

Buna benzer şekilde Eski Uygur hukuk belgelerinde yer alan bir başka deyim, köle azadıyla ilgili bir belgede yer alan ve kölenin özgür kaldıktan sonra istediği yere gidebileceğini belirtmek için kullanılan örü tagka kudı kumka bar- "yukarı dağa, aşağ1 çöle -istenilen herhangi bir yere- gitmek" deyimidir: örü tag-ka kudı kum-ka b(a)rsar tört yol-ı boş bolz-un (Y 82813-14) “...yukarı dağa, aşağı çöle gitse, dört yolu boş olsun, özgür kalsın." İlgili sözcüklerin (örü kudı) Eski Uygur Türkçesi metinlerinde aynı zamanda ikileme olarak kullanıldığı tespit edilmiştir (Şen, 2002, s. 226).

E4, bözçi: "Bez, pamuklu kumaş” karşılığında kullanılan böz (< Çin. 布 bù, GOÇ. $P u{ }^{2}<$ <r. $\left.\beta v ́ \sigma \sigma o \varsigma\right)$ Eski Uygur toplumunda oldukça geniş bir uygulama alanına sahiptir. ${ }^{4}$ Hukuk belgelerinde doğrudan "dokuma" anlamına gelecek şekilde sözleşmelere konu bir eşya olabildiği gibi para niyetine ödünç alındığı, vergilerin ödendiği ya da arazi, köle vb. satışılla elde edilebildiği, dolayısıyla ticari bir meta olarak kullanıldığı durumlar da söz konusudur. Ayrıca tüm bunlardan farklı olarak bözün Uygurlarda resim yapmak için tuval ya da yazı materyali olarak kullanılabildiği de ifade edilmektedir (Raschmann, 1995, s. 89 ve 92).

4 Sözcüğün Çincedeki varlığı ile ilgili olarak bk. bù 布 50:2 (Pulleyblank, 1991, s. 42). 
Böz sözcüğüne $\{+c ̧ I\}$ isimden isim yapım ekinin eklenmesiyle oluşan bözçi "bezci, dokumacı, dokuma yapan" anlamında bir meslek adıdır (Gabain, 1950, s. 60; Erdal, 2004, s. 148; Eraslan, 2013, s. 95). Bu ve benzeri meslek adlarının Eski Uygur toplumunda aynı zamanda birer şahıs adı olarak kullanılabileceği hukuk belgelerinden hareketle tespit edilebilmektedir: tanuk borlukçı (U 52308), biz torçı yolçı elçi üç ak-a inilär-niך (U 52379-10), bu nişan $m(\ddot{a}) n$ tanuk udçı-nıๆ ol (İstanbul $35_{25}$ ).

\subsection{Metin F: U 5826 (Glas: T III 518)}

1 ...] ulug bermiş kunpu $S / /$ '[...

...] 'wlwq pyrmyş qwnpw s//'[...

2 ...ay] sayu y(e)g(i)rmirär kuanpu asıgın [...

...] s'yw ykrmyr'r qw'npw "syq yn [...

3 ...] bolzun $m(\ddot{a}) n$ oglum' ' [...

...] pwlz wn mn 'wqlwm'/ [...

$4 \ldots] / Y R T$ tanuk sav (?) toja bu $n[$ işan...

...]/yrt t'nwq s'v twnk' pw n[...

${ }^{1-2}[\ldots]$ Ulug'un verdiği kunpu [...] ay sayarak (her ay için) yirmişer kuanpu faiziyle ${ }^{3-4}[\ldots]$ olsun. Ben, oğlum $[\ldots]$ Tanık Sav (?) Tona. Bu nişan $[\ldots]$

Notlar:

F2, asıgın: İfade edildiği üzere sözleşmelerde "faiz" karşılığı kullanılan sözcüklerden bir diğeri asıgdır. Gerek ED'de ve gerekse DTS'de asıg için yapılan açıklamalar "fayda, kâr" anlamları etrafında şekillenmektedir (ED, 1972, s. 244b; DTS, 1969, s. 60a). UW'de asıg, "kazanç" temel anlamı etrafında gelişen dört maddede açıklanmıştır: "1. (maddi) kazanç, yarar, fayda. 2. Faiz, getiri. 3. Kurtuluş (Budizm'de kurtuluş yolu için) kazanç, fayda. 4. (Maniheizm'de) hayır, (manevi) fayda." (2015, s. 294-298). Sözcük, ayrıca Eski Uygur Türkçesi metinlerinde ädgü ve tusu sözcükleriyle birlikte "fayda, yarar" anlamında ikileme olarak kullanılmıştır (Şen, 2002, s. 37; Ölmez, 2017, s. 253).

\subsection{Metin G: U 6047 / I. Sayfa}

1 ...iki]nti ay tokuz [y(e)]g(i)rmikä maya

...]nty "y twqwz [ ] $\mathrm{krmyk}^{\prime} \mathrm{m}^{\prime} \mathrm{nk}^{\prime}$

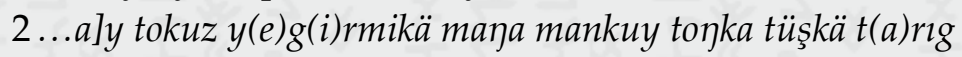

...]y twqwz ykrmyk' m'nk' m'nkwy twnk q' twyş k' tryq

${ }^{1}[\ldots]$ ikinci ayın on dokuzunda bana ${ }^{2}[\ldots]$ ayın on dokuzunda bana, Mankuy

Ton'a faiz (karşılığında) tahıl [...]

\subsection{Metin H: U 6186 / I. Sayfa}

1 tüşkä ta[r]l[g... twyş $\mathrm{k}^{\prime} \mathrm{t}^{\prime}[\mathrm{y}[\ldots$

2 bolup KWYRYÇW/[...

pwlwp kwyryçw/[...

3 şıg tarıg alt $[\imath \mathrm{im} . .$.

şyq t'ryq "1t $[\ldots$

${ }^{1-3}$ faiz karşılığında tahıl $[\ldots]$ olup $[\ldots]$ şıg tahıl aldım $[\ldots]$ 


\section{DİZİN}

al-

almak, sahip olmak

a.-dim A2, D1

a.-tım C2, H3 [=4]

alțun

ansun

arpa

äsän

asig

äv

ay
altin
a. A2 [=1]

şahıs adi
a. A2
a.+kä A1 [=2]

arpa, bir tür tahıl bitkisi

a. D1, D2 [=2]

şahıs adı

ä. B3 [=1]

faiz, kâr

a.+1n F2 [=1]

ev, bark

ä.+täkilär D4 [=1]

ay, ortalama otuz günlük süre
a. A4, B2, C1, C2, F2, G1, $\mathrm{G} 2[=7]$

bar

ber-

bilä

birlä var, mevcut

b. yok bolsar män A3

[=1]

vermek, teslim etmek

b.-ginçä A3, E2

b.-mädin D3

b.-miş F1

b.-ür män D2

b.-zün D4, E3, [=7]

ile, birlikte (krş. birlä)

b. E3 [=1]

ile, birlikte (krş. bilä) b. D4 [=1]

biz

biz, birinci çokluk şahıs

zamiri

b. E2, E5

örü kudı bolsar b. E2 [=3]

bol- olmak, yardımcı fiil

örü kudı b.-sar biz E2

bar yok b.-sar män A3

b.-up B5, H2

kärgäk b.-up A2

b.-zun F3 [=6]

borçı şarap tüccarı

b. E4 [=1]

bözçi bezci, dokumacı

b. E4 [=1]

bu

bu

b. A3, E5, F4 [=3]

burhan kulı şahıs adı

b. $\mathrm{C} 4[=1]$

iki

iki

i. $\mathrm{C} 1[=1]$

$\begin{array}{ll}\text { ikigü her ikisi } & \text { i. E2 [=1] }\end{array}$

ikinti ikinci

i. G1 [=1]

ini

küçük erkek kardeş i. $+\mathrm{m}$ E3 [ $=1]$

käçür- geçirmek

k.-sär män D3 [=1]

kärgäk gerek, lazım

k. bolup A2 [=1] 


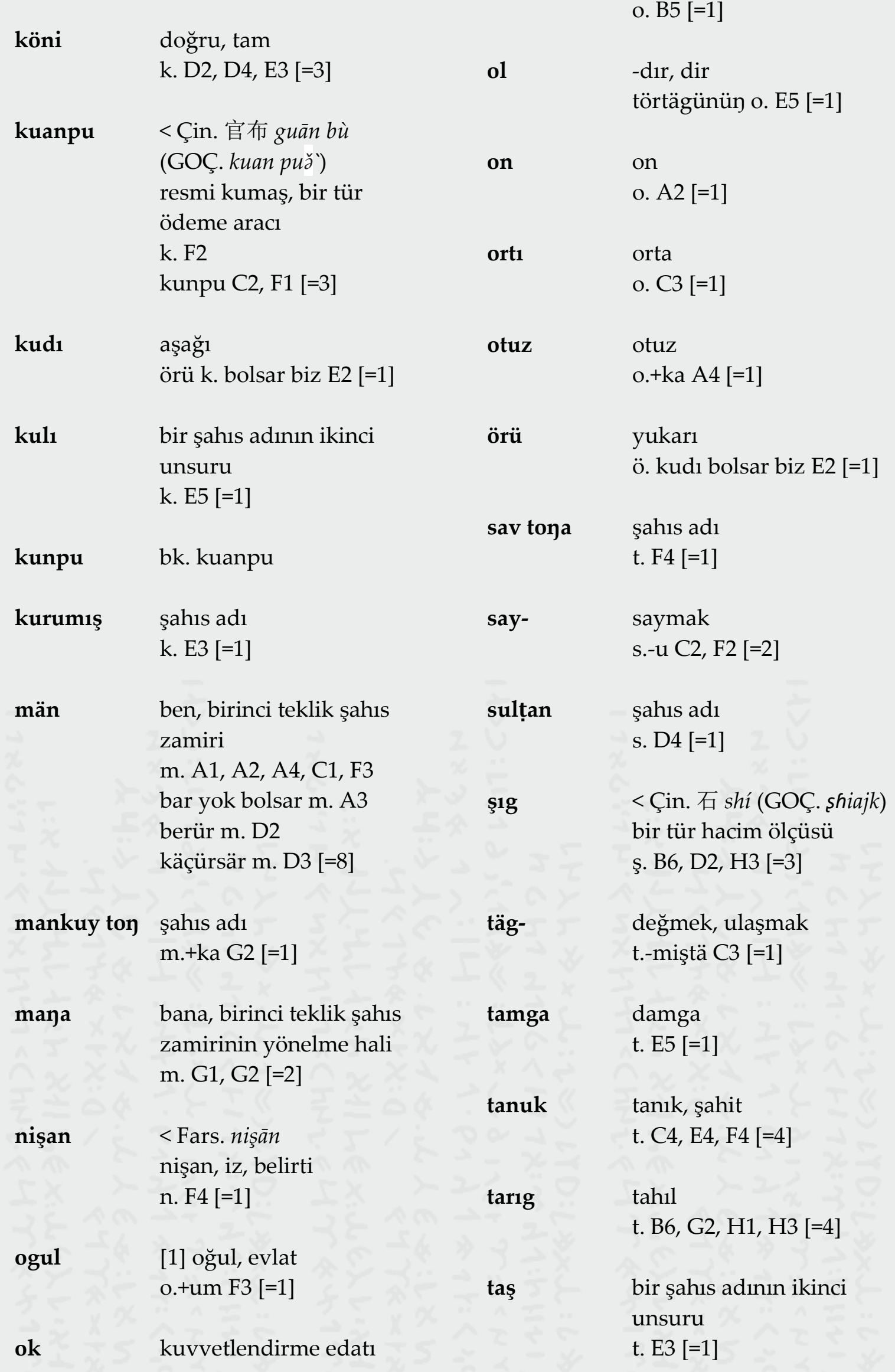




\begin{tabular}{|c|c|c|c|}
\hline tokuz & $\begin{array}{l}\text { dokuz } \\
\text { t. A1 [=1] }\end{array}$ & üçünç & $\begin{array}{l}\text { üçüncü } \\
\text { ü. B2 [=1] }\end{array}$ \\
\hline tokuz yegirn & $\begin{array}{l}\text { i on dokuz } \\
\text { t.+kä G1, G2 [=2] }\end{array}$ & yaya toya & $\begin{array}{l}\text { şahis adis } \\
\text { y. E4 [=1] }\end{array}$ \\
\hline tonuz & $\begin{array}{l}\text { domuz } \\
\text { t. A1 [=1] }\end{array}$ & yay1 & $\begin{array}{l}\text { gün } \\
\text { y.+ ka A1, C1 [=2] }\end{array}$ \\
\hline toyın tuțun & $\begin{array}{l}\text { şahıs adı } \\
\text { t. A4 [=1] }\end{array}$ & yegirmirär & $\begin{array}{l}\text { yirmişer } \\
\text { y. F2 [1] }\end{array}$ \\
\hline törtägü & $\begin{array}{l}\text { her dördü } \\
\text { t.+nün ol E5 [=1] }\end{array}$ & y1l & $\begin{array}{l}\text { y1l, sene } \\
\text { y. A1, C1 [=2] }\end{array}$ \\
\hline tüş & $\begin{array}{l}\text { faiz, fayda } \\
\text { t.+kä B4, G2, H1 [=3] }\end{array}$ & yok & $\begin{array}{l}\text { yok, mevcut olmayan } \\
\text { bar y. bolsar män A3 [=1] }\end{array}$ \\
\hline ulug & $\begin{array}{l}\text { şahıs adı } \\
\text { u. F1 [=1] }\end{array}$ & yüz & $\begin{array}{l}\text { yüz } \\
\text { y. C2 [=1] }\end{array}$ \\
\hline
\end{tabular}

Eski Uygur borç sözleşmeleri, hukuk belgesi olma özelliği taşıyan farklı içerikteki diğer sözleşmelerde olduğu gibi (satış, kira, takas vb.) belirli formüllere, kalıp ifadelere dayanarak hazırlanmıştır. Bunlar arasında ortaklık taşıyan bölümler olduğu gibi yalnızca ilgili alt gruba ait olan ve başka içeriklerde rastlanılmayan bölümler de mevcuttur. Tarihlendirme ve tanıklık bilgisi her sözleşmede yer alan temel ortak unsurken vergilendirme, sınır bilgisi, ürün paylaşımı, cezalandırma, teminat gösterme, kefalet gibi unsurlar bu kez farklı içeriklerin kendine ait bölümlerini oluşturur. Dolayısıyla bir sözleşme ya da benzeri herhangi bir hukuki belgeyi bütünlük taşımamasına ve hasarlı olmasına rağmen sahip olduğu ifadeler veya formüller doğrultusunda (bunların ilgili içeriği yansıtma durumuna göre) belirli gruplara yerleştirmek mümkün olmaktadır. Bu çalışmada yer alan sekiz metin parçasının her biri oldukça dar bir hacme sahip olmasına rağmen borç kategorisinde değerlendirilmesinin temel sebebi, işte bu görüşe dayanarak mevcut satırlarında onların niteliğini tanımlayabilecek sözcük veya deyimlere, ifadelere sahip olmasıdır. Buna göre bar yok bol- ve örü kudı bol- deyimleri, faiz için kullanılan asıg ve tüş sözcükleri ile hane halkını işaret eden ävtäkilär, borç sözleşmelerinin temel unsurları arasında yer alır. Bar yok bol- ile örü kudı bol-ifadelerinin esasta deyim olmasına rağmen sözleşmelerde kefillerin belirtildiği bölümlerde mutlaka kullanılması, yine "fayda, yarar" anlamı taşıyan asıg ve tüş sözcüklerinin anlam genişlemesiyle "faiz" anlamı kazanması ve ävtäkiler denilerek borçtan sorumlu tutulan bir insan topluluğu oluşturulması, tüm bunların temel anlamlarının, günlük dildeki kullanımlarının yanı sıra birer hukuki terim olma vasfı taşıdı̆̆ını göstermektedir. 


\section{EXTENDED ABSTRACT}

The main aim of this study is the transcription, transliteration and translation of the eight old Uyghur fragments preserved in the Turfan Collection in the BerlinBrandenburg Academy of Sciences and Humanities. However, when deemed necessary, several explanations were made, and an index was prepared. Although the texts are quite massless and do not contain integrity, the main reason for their inclusion in loan contracts is some keywords and terms they contain. Accordingly, each document with commercial content has a certain formula and/or stereotyped expression. They play a major role in detecting content. While the date and testimony information constitute common elements between contracts, the existence of information such as product sharing, border information, fines, and taxation varies. This variability is the main factor that helps the damaged texts to be classified by content determination. At least one keyword or phrase was identified in each of the texts examined in this study. Asıg and tüş words and ävtäkilär which denotes household, and the phrases such as bar yok bol- "to die" and örü kudı bol- "to run away, disappear" are among the key elements of loan contracts. Even though the expressions of bar yok bol- and örü kudı bol- are only idioms basically, they were used in the surety section of the contracts. Anew, the uses of the words asig and tüs, which basically means "advantage, benefit", in contracts in the sense of "interest" and finally creating a community responsible for the loan and its remark them indirectly as ävtäkilär; they show that these are legal terms alongside their daily life usage.

Loan contracts have a notable place among Uyghur legal documents in terms of both quality and quantity. Since Radloff, the majority of the contracts have been transcribed many times and various terms in the documents have been examined. The most significant aspect of contracts that differs from other commercial documents is that they provide information about interest and surety. Accordingly, in Old Uyghur Turkish, the Turkish words asıg and tüş were used for "interest", and the words paoşın and taypaoşın -of Chinese origin- were used in the meaning of "guarantor". It would be more accurate to interpret it as a "joint guarantor" since the people who are qualified as taypaoşins assume the responsibility for the payment of the loan and state it firsthand. While the contracts with these kinds of words are limited, the contracts, in which the debtor holds the entire household accountable for the loan along with one of his relatives, are more common. The households were implicitly stated as ävtäkilär, as stated above, and were held liable for the loan if the debtor died or ran away. As a result, these contracts are the primary sources that helped enlighten the social and commercial life of the period in terms of showing how the borrowing and loan practice in the daily life of the Old Uyghur society was realized. 


\section{KISALTMALAR}

\begin{tabular}{|c|c|c|}
\hline Ar. & : Arapça & \\
\hline bk. & : bakınız & \\
\hline $\mathrm{Ch} / \mathrm{U}$ & : chinesisch-uigurische texte & \\
\hline Çin. & : Çince & \\
\hline DLT & : Dîvânu Lugâti't-Türk, bk. Ercilasun-Akkoyunlu 2014 & \\
\hline DTS & : Drevnetyurkskiy Slovar', bk. Nadalyayev V.M., vd. 1969 & \\
\hline Ed & : Editör(ler) & \\
\hline ED & $\begin{array}{l}\text { : An Etymological Dictionary of Pre-thirteenth Century } \\
\text { Clauson } 1972\end{array}$ & Turkish, bk. \\
\hline Fars. & : Farsça & \\
\hline GOÇ. & : Geç Orta Çince & \\
\hline Gr. & : Grekçe & \\
\hline Haz. & : Hazırlayan(lar) & \\
\hline JSFO & : Journal de la Société Finno-Ougrienne & \\
\hline krş. & : Karşılaştırınız & \\
\hline Ot.Ry. & : Otani-Ryukoku & \\
\hline SI & : Ser india & \\
\hline TDK & : Türk Dil Kurumu & \\
\hline $\mathbf{U}$ & : uigurische texte & \\
\hline UW & : Uigurisches Wörterbuch, bk. Röhrborn 2015. & $=$ \\
\hline vb. & : ve benzeri & V \\
\hline vd. & : ve diğerleri & 2. \\
\hline VdSUA & : Veröffentlichungen der Societas Uralo-Altaica & 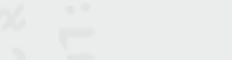 \\
\hline
\end{tabular}




\section{KAYNAKÇA}

Arat, R. R. (1964). Eski Türk hukuk vesikaları. JSFO (Sitzungsberichte der 6. arbeitstagung der PIAC in Helsinki 4.-8. 6. 1963), 65, 11-77.

Caferoğlu, A. (1938). Uygur sözlüğü, üçüncü bölüm S-Z. İstanbul: Burhaneddin Matbaası.

Clark, L. V. (1975). Introduction to the Uyghur civil documents of East Turkestan (13th-14th cc.) (Yayımlanmamış doktora tezi). Indiana University, Bloomington.

Clauson, G. (1972). An etymological dictionary of pre-thirteenth century Turkish. Oxford: Clarendon Press.

Eraslan, K. (2012). Eski Uygur Türkçesi grameri. Ankara: Türk Dil Kurumu Yayınları.

Ercilasun, A. B. \& Akkoyunlu, Z. (2014). Kâşgarlı Mahmud, Dîvânu Lugâti't-Türk, giriş-metinçeviri-notlar-dizin. Ankara: Türk Dil Kurumu Yayınları.

Erdal, M. (2004). A grammar of Old Turkic. Leiden: Brill.

Gabain, A. v. (1950). Alttürkische grammatik. Leipzig: Otto Harrassowitz.

Keskin, B. (2020). Eski Uygur Türkçesi hukuk belgeleri ve söz varlığı (Yayımlanmamış doktora tezi). İstanbul Üniversitesi, İstanbul.

Le Coq, A. (1918). Handschriftliche uigurische urkunden aus Turfan. Túrán, 449-460.

Malov, S. E. (1927). Dva Uygurskih dokumenta. Sbornik, V. V. Bartol'du, Turkestanskie druz'ya, uçeniki i poçitateli. Taşkent, 387-394.

Malov, S. E. (1932). Uygurskie rukopisnye dokumenty ekspedicii S. F. Ol'denburga. ZAPISKI Instituta Vostokovedeniya, Akademii Nauk I, 129-149.

Malov, S. E. (1951). Pamyatniki drevnetyurkskoy pis'mennosti. Teksty i issledoveniya. Moskova-Leningrad: Akademii Nauk.

Matsui, D. (1996). Mongoru jidai Uigurisutan no monjo gyōsei to zeisei, ekidensei. Uigurubun kyōshutsu meirei monjo wo chüshin to shite [Administration in Uighuristan under the Mongols] (Yayımlanmamış yüksek lisans tezi). Osaka University, Osaka.

Matsui, D. (1999). Mongoru jidai Uigurisutan no zeieki seido to monjo gyōsei [Taxation and administrative systems in Uiguristan under the Mongols (13th-14th cc.)] (Yayımlanmamış doktora tezi). Osaka University, Osaka.

Matsui, D. (2004). Unification of weight and measures by the Mongol empire as seen in the Uigur and Mongol documents. D. Durkin-Meisterernst \& S.-C. Raschmann \& J. Wilkens vd. (Ed.), Turfan Revisited-The First Century of Research into the Arts and Cultures of the Silk Road içinde (s. 197-202). Monographien zur Indischen Archäologie, Kunst und Philologie 17. Berlin: Dietrich Reimer Verlag.

Nadalyayev, V. M. vd. (1969). Drevnetyurkskiy slovar'. Leningrad: Nauka.

Ölmez, M. (2017). Eski Uygurca ikilemeler üzerine. Türk Dili Araştırmaları Yillığı-Belleten, 65(2), 243-311.

Pulleyblank, E. G. (1991). Lexicon of reconstructed pronunciation in Early Middle Chinese, Late Middle Chinese, and Early Mandarin. Vancouver: UBC Press.

Radloff, W. (1899). Altuigurische sprachproben aus Turfan. D. Klementz (Haz.), Nachrichten über die von der Kaiserlichen Akademie der Wissenschaften zu St. Petersburg im Jahre 1898 Ausgerüstete Expedition. Heft I içinde (s. 55-83). St. Petersburg: Akademii Nauk.

Radloff, W. (1906). Uigurische schriftstücke, in text und übersetzung. A. Grünwedel (Haz.), Bericht über archäologische Arbeiten in Idikutschari und Umgebung im Winter 1902-1903 içinde (s. 181-195). Münih: Verlag der K. B. Akademie der Wissenschaften.

Radloff, W. (1928). Uigurische sprachdenkmäler. S. E. Malov (Haz.). Leningrad: Verlag der Akademie der Wissenschaften der USSR.

Ramstedt, G. J. (1940). Four Uigurian documents. C. G. Mannerheim (Ed.), Across Asia from West to East in 1906-1908 II içinde (s. 1-12). Helsinki: Suomalis-Ugrilainen Seura. 
Raschmann, S.-C. (1995). Baumwolle im türkischen zentralasien. Philologische und wirtschaftshistorische untersuchungen anhand der vorislamischen uigurischen texte. VdSUA 44. Wiesbaden: Harrassowitz Verlag.

Raschmann, S.-C. (2007). Alttürkische handschriften teil 13, dokumente teil 1. VOHD 13,21. Stuttgart: Franz Steiner Verlag.

Raschmann, S.-C. (2009). Alttürkische handschriften teil 14, dokumente teil 2. VOHD 13,22. Stuttgart: Franz Steiner Verlag.

Röhrborn, K. (2015). Uigurisches wörterbuch, sprachmaterial der vorislamischen türkischen texte aus zentralasien -neubearbeitung- II. nomina-pronomina-partikeln, band 1: a asvik. Stuttgart: Franz Steiner Verlag.

Şen, S. (2002). Eski Uygur Türkçesinde ikilemeler (Yayımlanmamış yüksek lisans tezi). Ondokuz Mayıs Üniversitesi, Samsun.

Tuguşeva, L. Y. (2013). Uygurskie delovye dokumenty X-XIV. iz vostoçnogo Turkestana, Moskova: Nauka.

Vér, M. (2016). The postal system of the Mongol empire in Northeastern Turkestan (Yayınlanmamış doktora tezi). University of Szeged, Doctoral School of History, Szeged.

Yamada, N. (1965). Uigurubun taishaku keiyakusho no shoshiki [The forms of the Uighur documents of loan contracts]. Ōsaka daigaku bungakubu kiyō [Memoirs of the Faculty of Letters, Osaka University], 11, 87-216.

Yamada, N. (1993). Sammlung uigurischer kontrakte I-III. J. Oda \& P. Zieme \& H. Umemura \& T. Moriyasu (Haz.). Osaka: Osaka University Press. 


\section{EKLER}

\section{TIPKIBASIM}

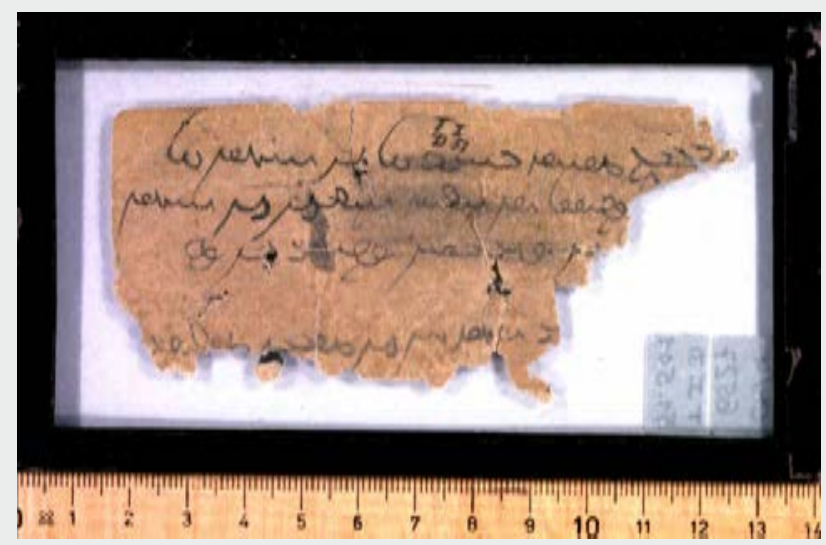

Metin A: Ch/U 6527 (T I D 51)

(c) Depositum der Berlin-Brandenburgische Akademie der Wissenschaften in der

Staatsbibliothek zu Berlin-Preußischer Kulturbesitz, Orientabteilung

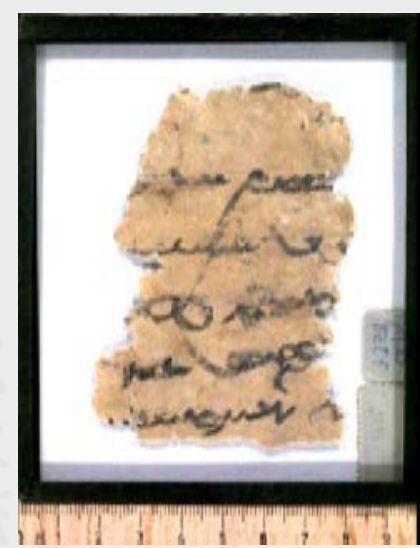

Metin B: Ch/U 7358 v (Glas: T II T 1972)

(c) Depositum der Berlin-Brandenburgische Akademie der Wissenschaften in der Staatsbibliothek zu Berlin-Preußischer Kulturbesitz, Orientabteilung

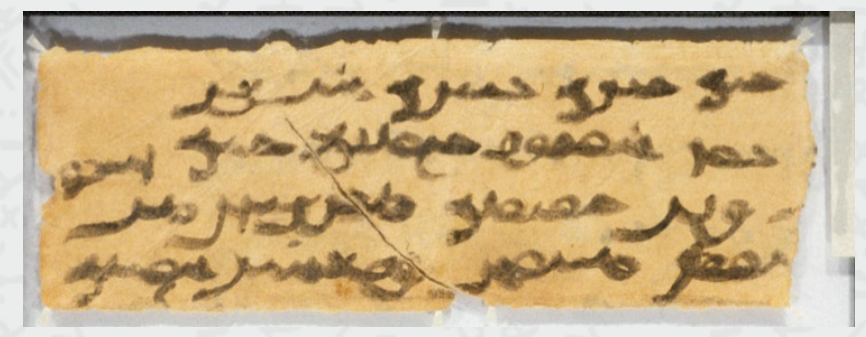

Metin C: So 10239 (4) v (T I a)

(C) Depositum der Berlin-Brandenburgische Akademie der Wissenschaften in der Staatsbibliothek zu Berlin-Preußischer Kulturbesitz, Orientabteilung 


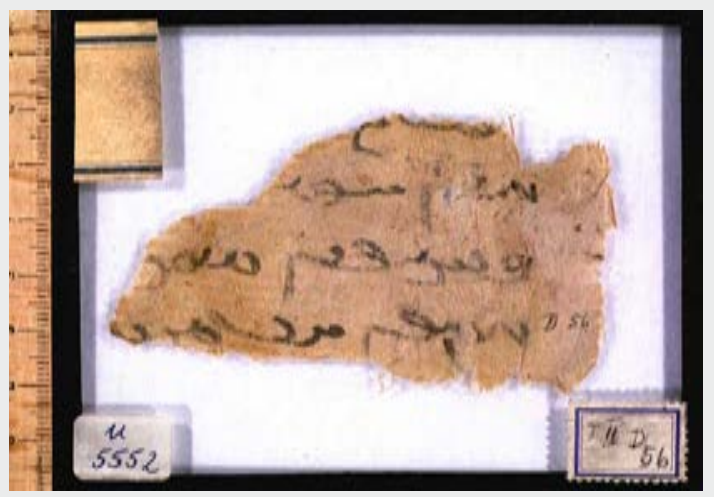

Metin D: U 5552 (T II D 56)

(C) Depositum der Berlin-Brandenburgische Akademie der Wissenschaften in der Staatsbibliothek zu Berlin-Preußischer Kulturbesitz, Orientabteilung

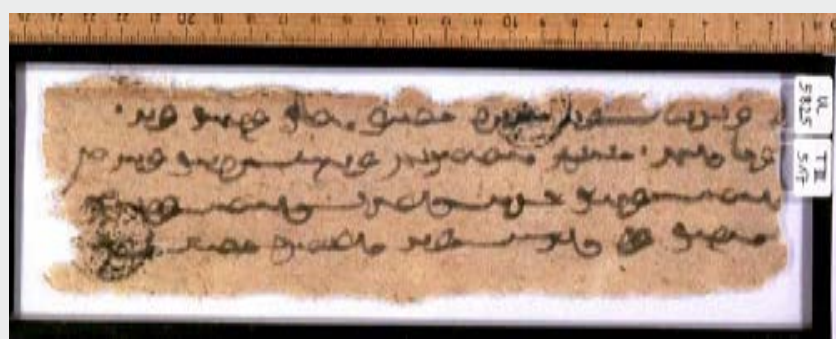

Metin E: U 5825 (Glas: T III 517)

(C) Depositum der Berlin-Brandenburgische Akademie der Wissenschaften in der Staatsbibliothek zu Berlin-Preußischer Kulturbesitz, Orientabteilung

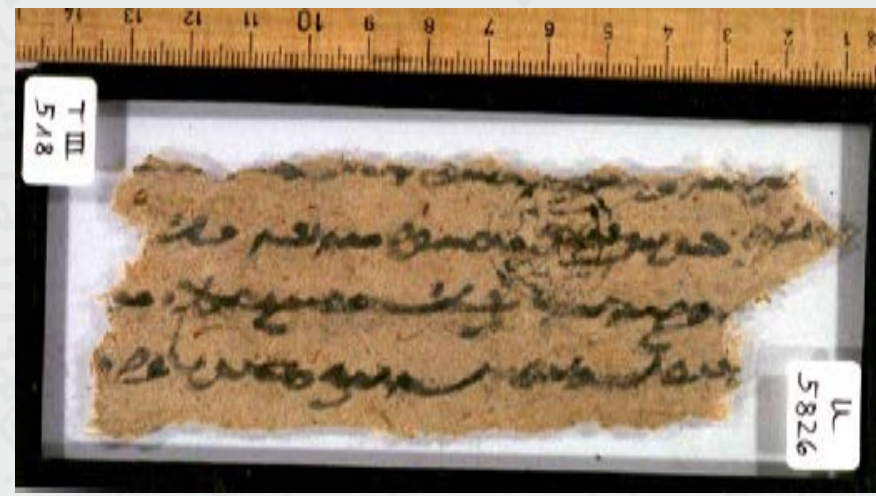

Metin F: U 5826 (Glas: T III 518)

(C) Depositum der Berlin-Brandenburgische Akademie der Wissenschaften in der Staatsbibliothek zu Berlin-Preußischer Kulturbesitz, Orientabteilung 


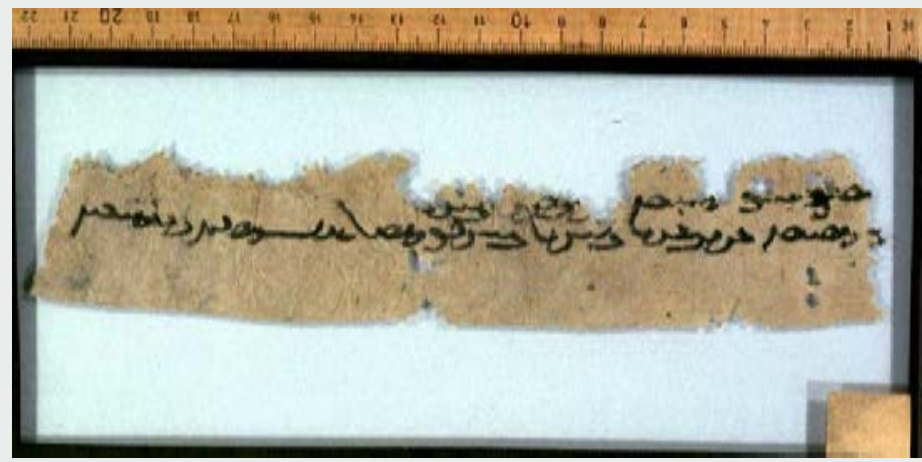

Metin G: U 6047 / I. Sayfa

(c) Depositum der Berlin-Brandenburgische Akademie der Wissenschaften in der Staatsbibliothek zu Berlin-Preußischer Kulturbesitz, Orientabteilung

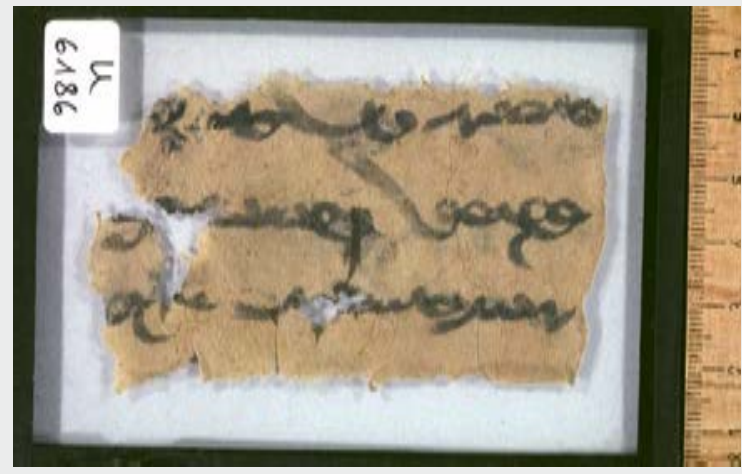

Metin H: U 6186 / I. Sayfa

(C) Depositum der Berlin-Brandenburgische Akademie der Wissenschaften in der Staatsbibliothek zu Berlin-Preußischer Kulturbesitz, Orientabteilung 